\title{
CORRECTION OF THE UNFAVOURABLE EFFECTS OF VASOPRESSIN BY NITROGLYCERIN INFUSION
}

\author{
V. Lanza, 1. Demma, A. Call, and G. Castronovo
}

\section{ABSTRACT}

\begin{abstract}
Nitroglycerin was administered with vasopressin to prevent adverse effects. Vasopressin $0.25 \mathrm{U} \cdot 70 \mathrm{~kg}^{-1} \cdot \mathrm{min}^{-1}$ was infused intravenously in four dogs for 40 minutes, when a venous infusion of nitroglycerin $1.2 \mu \mathrm{g} \cdot \mathrm{kg}^{-1} \cdot \mathrm{min}^{-1}$ was added for 20 minutes. Nitroglycerin $1.2 \mu \mathrm{g} \cdot \mathrm{kg}^{-1} \cdot \mathrm{min}^{-1}$ alone was infused intravenously in another four dogs for 40 minutes. The venous blood pressures (mesenteric and central) and arterial pressures (mesenteric and femoral), the electrocardiogram and arterio-venous difference were recorded. Nitroglycerin was shown to annul the unfavourable effects of vasopressin without altering its efficacy upon portal pressure.
\end{abstract}

KeY Words: Pharmacology, vasopressin, nitroglycerin.

A GREAT DEAL of literature has been published proving the effectiveness of vasopressin (VSP) in the treatment of upper gastrointestinal haemorrhage in cirrhotic patients with portal hypertension. It is known that the use of this drug is often limited by the appearance of undesirable side effects,' the frequency and severity of which do not seem to be affected by selective infusion into the superior mesenteric artery which has been used instead of intravenous administration. ${ }^{2}$

Some interest has recently been shown in the proposal for simultaneous administration of vasopressin with either isoproterenol ${ }^{3}$ dopamine, ${ }^{4}$ sodium nitroprusside, ${ }^{5}$ or glucagone, ${ }^{5}$ to neutralize the undesirable effects of vasopressin without altering its effectiveness. With this aim in mind we chose nitroglycerin to counteract the side effects of vasopressin, since it is well known that it has beneficial vasoactive properties on the central and splanchnic haemodynamics in man, without causing toxicity and tachyphylaxis. ${ }^{6,7}$

\section{Material ANd Methods (Table 1)}

Eight dogs weighing between 18 and $22 \mathrm{~kg}$ were used in our experiment. The animals had been kennelled in identical conditions and had

V. Lanza, M.D., I. Demma, M.D., A. Cali, M.D. G. Castronovo, M.D., Department of Anaesthesia, Surgical Clinic III, University of Palcrmo, Palermo, Italy.

Address for correspondence: Dott. Vincenzo Lanza, Via Libertà 163, 90143 Palermo, Italy. not been fed for 12 hours. They were brought into the operating theatre and were given intravenous preanaesthetic medication with fentanyl $1.2 \mu \mathrm{g} \cdot \mathrm{kg}^{-1}$ and atropine $10 \mu \mathrm{g} \cdot \mathrm{kg}^{-1}$, which were injected into a vein of a front leg.

The dogs were then anaesthetized with thiopentone $5 \mathrm{mg} \cdot \mathrm{kg}^{-1}$ for induction, the trachea was intubated and ventilation was controlled using pancuronium bromide $70 \mu \mathrm{g} \cdot \mathrm{kg}^{-1}$ for muscle relaxation. Anaesthesia was maintained with a gaseous mixture of $61 \cdot \mathrm{min}^{-1}$ of $\mathrm{FI}_{\mathrm{O}_{2}} 0.35$ and $\mathrm{FI}_{\mathrm{N}_{2} \mathrm{O}} \mathrm{O} 0.65$, given in a non-rebreathing system, with a ventilatory frequency of 18 per minute. Additional doses of pancuronium bromide $14 \mu \mathrm{g} \cdot \mathrm{kg}^{-1}$ allowed controlled ventilation to be maintained with satisfactory relaxation.

After midline laparotomy a $1.0 \mathrm{~mm}$ catheter $3 \mathrm{~cm}$ long was introduced into the superior mesenteric artery and through the right femoral vein, previously isolated, the right atrium was reached by means of a $1.2 \mathrm{~mm}$ polyethylene catheter $75 \mathrm{~cm}$ long; the correct placement of the atrial catheter was confirmed by an intracavity electrocardiogram usng the liquid electrode technique $^{8}$ (Figure 1); the mean venous blood pressures were measured with a water manometer, while the mean arterial pressures were measured with mechanical transducers (Pressurveil Concept); zero level for all pressure recordings was chosen $10 \mathrm{~cm}$ dorsal to the sternal angle.

All connections were kept patent by periodic washing with a 0.9 per cent saline solution containing heparin $\left(1250 \mathrm{U} \cdot 1^{-1}\right)$, of which 
TABLE

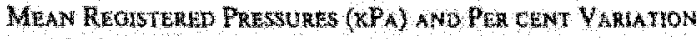

\begin{tabular}{|c|c|c|c|c|c|c|c|}
\hline Time & Minutes) & 0 & 40 & 60 & $0 \rightarrow 40$ & $40 \rightarrow 60$ & $0 \stackrel{4 \%}{0}$ \\
\hline Pots: & $\begin{array}{l}\text { Group } 1 \\
\text { Group } 2\end{array}$ & $\begin{array}{l}18,2=15 \\
173\end{array}$ & $\begin{array}{l}19.7 \pm 1.8 \\
10.9 \pm 0.2\end{array}$ & $16.9=15$ & $\begin{array}{l}+8 \pm 1 \\
-35 \pm 5\end{array}$ & $-13+7^{*}$ & $-6 \geq 6$ \\
\hline Pam & $\begin{array}{l}\text { Group } 1 \\
\text { Group } 2\end{array}$ & $\begin{array}{l}179 \pm 15 \\
17.3 \pm 1\end{array}$ & $193=13$ & $166=15$ & $\begin{array}{c}-13 \geq 8 \\
-36.5 \pm 5 *\end{array}$ & $-13=8$ & $-6+8$ \\
\hline CVP & Group 1 & $\begin{array}{l}0.39 \pm 0.13 \\
0.37 \pm 0.07\end{array}$ & $\begin{array}{l}0.29=0.09 \\
0.29=0.05\end{array}$ & $0.29 \leq 0.07$ & $\begin{array}{l}-22 \pm 5 \\
-20 \pm 3\end{array}$ & $+1 \pm 11$ & $-19+9$ \\
\hline $\mathrm{PV} \mathrm{m}$ & $\begin{array}{l}\text { Group } 1 \\
\text { Group } 2\end{array}$ & $\begin{array}{l}0.98=003 \\
0.94=005\end{array}$ & $\begin{array}{l}0.51=0.01 \\
0.83=0.07\end{array}$ & $0.53 \pm 0.0$ & $\begin{array}{r}-46 \pm 3 \\
-10 \pm x\end{array}$ & $+2+12$ & $-45 \pm 5 *$ \\
\hline
\end{tabular}

$* \mathrm{p}=0.05$

$* 0<0.01$

$P_{\text {as }}=$ systemic ateral pressure.

Pam $=$ Mesentenic arterial pressure.

CVP $=$ central venous pressare.

PVm = mesenteric venows pressure.

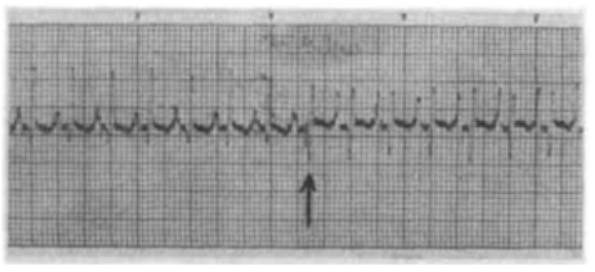

TouRE 1 Kute arrum lowalizaton by means of the etectrocardogram. The amow indicates wher the catheter has entered late atring

$50 \mathrm{~m}$ had been administered by the time the experiment had been concluded

Vasopressin $\left(0.25 \mathrm{U} 70 \mathrm{~kg}^{-1} \mathrm{~min}^{-1}\right)$ was ad. ministered to four animals (Group 1) for 40 minutes, by infusion of 0.9 per cent saline solution containing 100 of $6-1 y \sin$ yasopressin (Sandoz) in $250 \mathrm{mi}$. At 40 minutes nitroglycen $\left(1.2 \mu \mathrm{g}^{-1}-\mathrm{min}^{-1}\right)$ was added for 20 minutes. using $1.75 \mathrm{mg}$ of trintroglycerin (Venitrin Simes) diluted in $100 \mathrm{~m}$ of 0.9 per cent aline solution.

Io contrast only nitroglycerin was adminstered to the other four animals (Croup 2) for 40 muntes, all other arrangements being similar to the first group. Mean mesenteric and systemic arterial and venous pressures were recorded every 10 minute in both groups, for a total of 60 minutes in group 1, and for 40 minutes in group 2. An electrocardiogram (lead $\mathrm{l}$, was done in the first group at zero, forty and sinty minutes and in the second group at zero and forty minutes; at these same times a blood sample was taken from the right atrum and another one second later from the femoral antery.
The haemoglobin concentration (eyanomethaemoglobin method) and $\mathrm{So}_{2}$ (Macroreflectometer oxymeter-Optical Corporation) were detcrmined in ordet to estimate the content and the arteriovenous difference of oxygen $\mathrm{C}(\mathrm{a}-\mathrm{v}) \mathrm{O}_{2}$.

$\mathrm{C}$ (a-v) $\mathrm{O}_{2}$ was defermined by the integration of the differental equation:

$$
\int \frac{\left(d\left(C a_{2} \mathrm{n}-\mathrm{CV}_{\mathrm{O}_{2}}\right)\right.}{d t}=
$$

and by calculation of the time constint ( $\tau$ ) of the exponential growth function $\mathrm{Cam}-\mathrm{Cl}_{O_{2}}=$ $\left(\mathrm{Ca}_{0} \mathrm{~T}-\mathrm{CV}\right)\left(1 \mathrm{e}^{\mathrm{kt}}\right)$ from which the previous differential equation derives.

In both expressions.

$\mathrm{Ca}_{\mathrm{o}} \mathrm{m}=$ arterial content of oxygen (medsured) $\mathrm{Ca}_{0} \mathrm{~T}=$ theorefical arterial content of oxygen (Sa, 100 per cent) for the blood being examined

$\omega_{0}=$ mixed veauss content of oxygen (measured)

$$
t=1 \text { second. }
$$

The result obtained were subjected to stutistical analysis (SD, paired test); $\mathrm{p}=0,05$ was chosen as the lowest level of significance.

\section{RESULTS}

Systemic artetial presure (Figure 2, Table 1)

Cromp lt the infusion of vasopressin caosed a gradual Inerease of the systemic arterial pressure which reached $199 \pm 15 \mathrm{kPa}$ at 20 minutes from a baseline of $18 \mathrm{2} \pm 1.5 \mathrm{kPa}$, and stabilized 


\section{$\mathrm{mmHg} \mathrm{KPa}$}

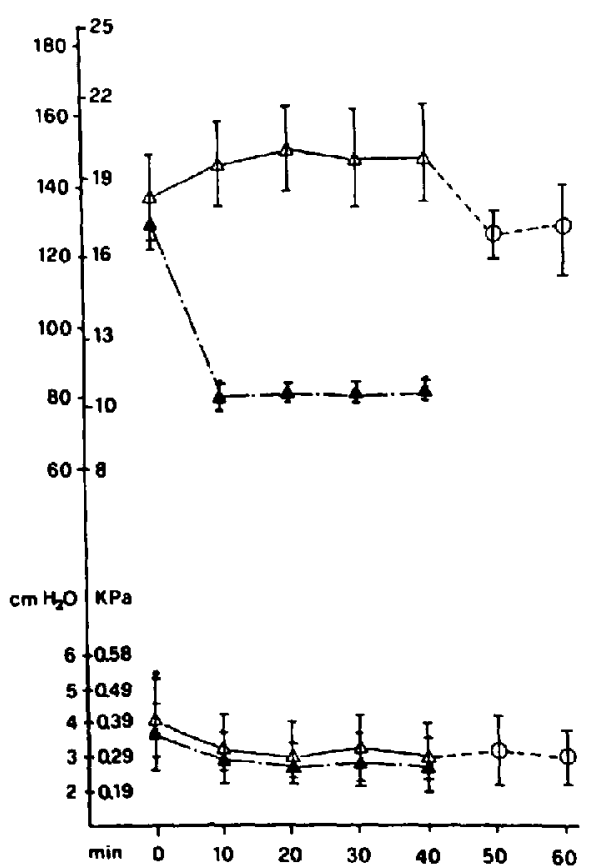

FIGURE 2 Arterial systemic pressure (Pas) above; central venous pressure (CVP) below.

$\Delta-\Delta=$ vasopressin: $0-.0=$ vasopressin + nitroglycerin: $\mathbf{A}-\cdot-\mathbf{\Lambda}=$ nitroglycerin.

at 40 minutes at $19.7 \pm 1.8 \mathrm{kPa}$ at 40 minutes being an increase of $8 \pm 1$ per cent compared to base value. The infusion of vasopressin and nitroglycerin, begun at forty minutes, caused a gradual decrease of systemic arterial pressure which had reached $16.9 \pm 1.5 \mathrm{kPa}$ at sixty minutes, being a decline of $13 \pm 7$ per cent ( $\mathrm{p}=$ 0.05 ) compared with 40 minutes and of $6 \pm 6$ per cent in comparison to base line.

Group 2: the administration of only nitroglycerin caused the usual fall of systemic arterial pressure which was $10.9 \pm 0.2 \mathrm{kPa}$ at 40 minutes compared to the base line of 17.3 $\pm 1 \mathrm{kPa}$, a decline of $35 \pm 5$ per cent $(\mathrm{p}<0.01)$

Central venous pressure (Figure 2, Table I)

Group 1: the central venous pressure decreased after the infusion of vasopressin from an initial value of $0.39 \pm 0.13 \mathrm{kPa}$ to $0.29 \pm$ $0.09 \mathrm{kPa}$ at forty minutes, being a decrease of 22 \pm 5.5 per cent. The combined administration of vasopressin and nitroglycerin had little influence on these changes in central venous pressure; in fact it was $0.29 \pm 0.07 \mathrm{kPa}$ at 60 minutes, an increase of $1 \pm 11$ per cent, compared to 40 minutes but a decrease of $19 \pm 9$ per cent in comparison to base values.

Group 2: the infusion of nitroglycerin caused a reduction of $20 \pm 3$ per cent in central venous pressure which reached $0.29 \pm 0.05 \mathrm{kPa}$ at 40 minutes from $0.37 \pm 0.07 \mathrm{kPa}$ at control.

Mesenteric arterial pressure (Figure 3, Table 1)

Group 1: The mesenteric arterial pressure followed the same pattern as the systemic arterial pressure on administration of vasopressin; in fact, from a base value of $17.9 \pm 1.5 \mathrm{kPa}$, it reached $19.9 \pm 1.5 \mathrm{kPa}$ at 20 minutes, and 19.3 $\pm 1.3 \mathrm{kPa}$ at 40 minutes, an increase of $7 \pm 2$ per cent. The combined infusion of vasopressin and nitroglycerin produced a decrease of the mesenteric arterial pressure which had stabilized at $16.6 \pm 1.5 \mathrm{kPa}$, at 60 minutes, a diminution of $13 \pm 8$ per cent $(p<0.05)$ compared with the pressure at 40 minutes and a reduction of $6 \pm 8$ per cent in comparison with baseline.

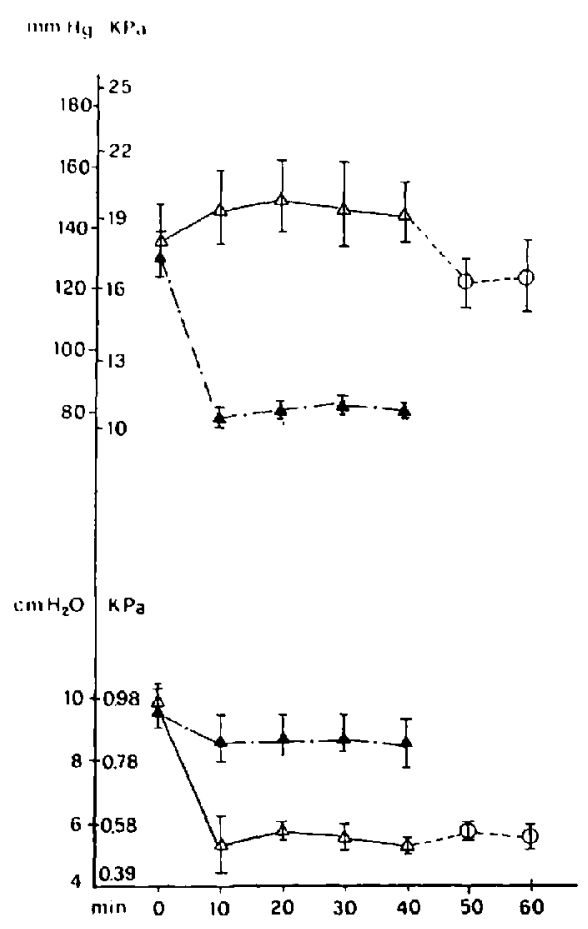

FIGURE 3 Mesenteric artieral pressure (Pam) above; mesenteric venous pressure ( $\mathrm{PVm}$ ) below. $\Delta-\Delta=$ vasopressin: $0--O=$ vasopressin + nitroglycerin: $\mathbf{\Lambda}-\cdot-\boldsymbol{\Lambda}=$ nitroglycerin. 
TABLE II

Heart Rate (Beats per minute), Arteriovenous Oxygen Difference $\left(m m o l \cdot 1^{-1}\right.$ ), Time constant $(\tau)$ (seconds) of the FunCtion $\mathrm{Ca}_{\mathrm{O}_{2}} \mathrm{~m}-\mathrm{C} \overline{\mathrm{v}}_{\mathrm{O}_{2}}=\left(\mathrm{Ca}_{\mathrm{O}_{2}} \mathrm{~T}-\mathrm{C}_{\mathrm{O}_{2}}\right)\left(1-\mathrm{e}^{\mathrm{k} i}\right)$ AND PerCentaGe VARIATION.

\begin{tabular}{lccccccc}
\hline & & & & & $\Delta \%$ & $\Delta \%$ & $\Delta \%$ \\
Time & (Minutes) & \multicolumn{1}{c}{0} & 40 & 60 & $0-40$ & $40-60$ & $0-60$ \\
\hline HR & Group 1 & $192 \pm 15$ & $144 \pm 34$ & $168 \pm 22$ & $-22 \pm 16^{*}$ & $+15 \pm 15$ & $-13 \pm 10$ \\
& Group 2 & $196 \pm 4$ & $193 \pm 4$ & & $-1 \pm 2$ & & \\
C(a-v)c 2 & Group 1 & $1.33 \pm 0.6$ & $1.6 \pm 0.4$ & $1.74 \pm 0.75$ & $+22 \pm 21$ & $+1 \pm 19$ & $+23 \pm 29$ \\
& Group 2 & $1.93 \pm 0.49$ & $1.69 \pm 0.49$ & & $-11 \pm 7$ & & \\
$\tau$ & Group 1 & $0.61 \pm 0.1$ & $0.51 \pm 0.05$ & $0.56 \pm 0.06$ & $-13 \pm 12$ & $+9 \pm 12$ & $-4 \pm 14$ \\
& Group 2 & $0.47 \pm 0.06$ & $0.54 \pm 0.07$ & & $+24 \pm 45$ & & \\
\hline
\end{tabular}

$*_{p}<0.05$

Group 2: The administration of nitroglycerin caused a considerable fall of mesenteric arterial pressure which declined from $17.3 \pm 1 \mathrm{kPa}$ to $10.7 \pm 0.2 \mathrm{kPa}$ at 40 minutes, a decrease of $36 \pm$ 5 per cent $(p<0.01)$ compared with the base value.

Mesenteric venous pressure (Figure 3, Table I) Group 1: After the infusion of vasopressin, a fall of mesenteric venous pressure was observed from the base value of $0.98 \pm 0.3 \mathrm{kPa}$, to $0.56 \pm$ $0.01 \mathrm{kPa}$ at 20 minutes and to $0.51 \pm 0.01 \mathrm{kPa}$ at 40 minutes. Compared with the base value, the reduction at this time was $46 \pm 3$ per cent ( $\mathrm{p}<$ $0.01)$. The combined infusion of vasopressin and nitroglycerin, begun at 40 minutes, caused a negligible elevation of mesenteric venous pressure which reached $0.05 \pm 0.03 \mathrm{kPa}$ at 60 minutes, an increase of $2 \pm 12$ per cent compared with 40 minutes, a reduction of $45 \pm$ 5 per cent $(\mathrm{p}<0.01)$ in comparison with base values.

Group 2: Nitroglycerin caused a reduction of $10 \pm 3$ per cent of the mesenteric venous pressure which went from $0.94 \pm 0.05$ to $0.83 \pm$ $0.07 \mathrm{kPa}$ after 40 minutes.

Variation of heart rate (Figure 4, Table II).

Group 1: Bradycardia occurred during the infusion of vasopressin; in fact the heart rate fell by $22 \pm 16$ per cent $(p<0.05)$, going from base values of $192 \pm 15 / \mathrm{min}$ to $144 \pm 34 / \mathrm{min}$ at 40 minutes.

The combined administration of vasopressin and nitroglycerin brought the heart rate back to the normal values which had reached $168 \pm$ $22 / \mathrm{min}$ at 60 minutes an increase of $15 \pm 15$ per cent compared with the rate at 40 minutes and a decrease of $13 \pm 10$ per cent compared to base values.

Group 2: The isolated administration of nitro-

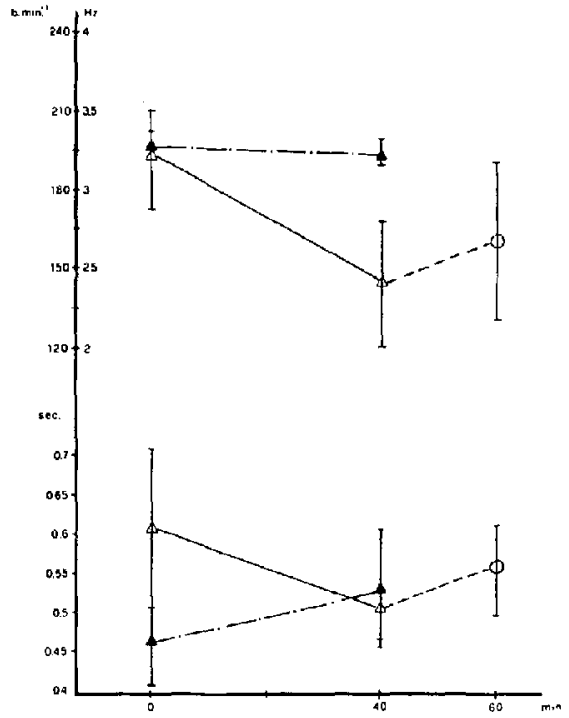

FIGURE 4 Heart rate above; Time constant of $\mathrm{Ca}_{\mathrm{O}_{2}} \mathrm{~m}-\mathrm{C} \overline{\mathrm{V}}_{\mathrm{O}_{2}}=\left(\mathrm{Ca}_{\mathrm{O}_{1}} \mathrm{~T}-\mathrm{C} \overline{\mathrm{v}}_{\mathrm{O}_{2}}\right)\left(1-\mathrm{e}^{-\mathrm{kT}}\right)$ below $\Delta-\Delta=$ vasopressin: $O \ldots=$ vasopressin + nitroglycerin: $\boldsymbol{\Delta} \cdot-\boldsymbol{\Delta}=$ nitroglycerin.

glycerin did not produce any important variations of heart rate which went from a base value of $196 \pm 4 / \mathrm{min}$ to $193 \pm 4 / \mathrm{min}$ at 40 minutes, a decrease of $1 \pm 2.5$ per cent. In neither group were electrocardiogram changes noted.

Arterio-venous oxygen difference (Table II)

Group 1: An increase of arterio-venous oxygen difference was seen during the administration of vasopressin; it went from a base value of $1.33 \pm 0.6 \mathrm{mmol} \cdot 1^{-1}$ to $1.6 \pm 0.4 \mathrm{mmol} \cdot 1^{-1}$ at 40 minutes, a rise of $22 \pm 21$ per cent.

The association of vasopressin with nitroglycerin brought the arterio-venous oxygen dif- 
ference to $1.74 \mathrm{mmol} \cdot 1^{-1}$, an increase of $1 \pm 19$ per cent, compared to 40 minutes and of $23 \pm 29$ per cent in comparison with base values.

Group 2: During the infusion of nitroglycerin there was a fall of arterio-venous oxygen difference from a base value of $1.93 \pm 0.49 \mathrm{mmol} \cdot 1^{-1}$ to $1.69 \pm 0.49 \mathrm{mmol} \cdot 1^{-1}$ after 40 minutes of administration. The registered decrease was $11 \pm 7$ per cent.

Time constant of the function $\left(\mathrm{Ca}_{\mathrm{O}_{2}} \mathrm{~m}-\mathrm{C}_{\mathrm{O}_{2}}=\right.$ $\left(\mathrm{Cv}_{\mathrm{O}_{2}} \mathrm{~T}-\mathrm{C}_{\mathrm{O}_{2}}\right)\left(1-\mathrm{e}^{-\mathrm{kt}}\right)$. Figure 4, Table $\left.\mathrm{U}\right)$

Group I: The time constant $(\tau)$ of the exponential growth function used to analyze the variations of the arterio-venous oxygen difference showed a diminution of $13 \pm 12$ per cent during the infusion of vasopressin, decreasing from an initial $0.61 \pm 0.1 \mathrm{sec}$ to $0.51 \pm 0.05 \mathrm{sec}$ at forty minutes.

During the infusion of vasopressin and nitroglycerin the time constant increased, reaching $0.56 \pm 0.06 \mathrm{sec}$ at 60 minutes, a rise of $9 \pm 12$ per cent compared to 40 minutes, and a reduction of $4 \pm 14$ per cent against base value.

Group 2: During administration of nitroglycerin there was an increase of the time constant. From the initial value of $0.47 \pm 0.06 \mathrm{sec}$ it reached $0.54 \pm 0.07$ at 40 minutes, a rise of 24 \pm 45 per cent compared to base line.

\section{Discussion}

The hypertensive effects of vasopressin were offset by nitroglycerin; the combination of the two agents reduced the rise of pressure registered after the administration of vasopressin alone by $13 \pm 7$ per cent $(p=0.05)$ and brought it back to base levels. This demonstrates how easily this combination can restore the arterial balance with the doses we have used. This becomes more evident when one considers the results of the isolated infusion of nitroglycerin, which caused a reduction of systemic arterial pressure of $35 \pm$ 5 per cent $(\mathrm{p}<0.01)$ as opposed to a decrease of only $6 \pm 6$ percent produced by the combination of vasopressin and nitroglycerin, though the doses of nitroglycerin were the same in both groups.

These considerations are also valid for the mesenteric arterial pressure which registered similar variations.

The effects of vasopressin and nitroglycerin on venous pressure are particularly interesting. During the administration of vasopressin alone central venous pressure registered a decrease of
$22 \pm 5$ per cent and combined infusion of vasopressin and nitroglycerin did not substantially alter this reduction, which was still $19 \pm 9$ per cent at 60 minutes compared to base values.

This result, if considered together with the decrease of $20 \pm 3$ per cent in central venous pressure during the infusion of only nitroglycerin, shows that vasopressin and nitroglycerin administered separately have a similar effect on the central venous pressure, without synergism when the two drugs are combined. This phenomenon can be explained when one considers that vasopressin and nitroglycerin, if administered separately, can induce a reduction in the venous return and in cardiac output, but have a different effect on after-load:1,7,9 vasopressin increases peripheral resistance, whereas nitroglycerin reduces it. The balance of the pressure effects observed for systemic and mesenteric arterial pressure could therefore explain the absence of synergism of action of vasopressin and nitroglycerin on central venous pressure. However, central venous pressure data show no statistically significant difference $(p=0.1)$.

The $46 \pm 3$ per cent $(p<0.01)$ reduction of mesenteric venous pressure by vasopressin was not influenced by the administration of nitroglycerin. The association of vasopressin with nitroglycerin showed a drop in mesenteric venous pressure of $45 \pm 5$ per cent $(p<0.01)$ in group 1 as compared with control values, whereas in group 2 the infusion of nitroglycerin alone produced a reduction of mesenteric venous pressure of $10 \pm 3$ per cent, which is modest and statistically not significant $(p<0.1)$ considering that, at the same time, there was a decrease of 36 \pm 5 per cent $(p<0.01)$ of the mesenteric arterial pressure.

In a few dogs, double or triple doses of nitroglycerin were added after vasopressin. Compared to group 1 there was significant reduction in venous mesenteric pressure besides the important decrease of arterial systolic pressure. Nitroglycerin proved also to have a positive effect on the heart rate, which was reduced by $22 \pm 16$ per cent $(p<0.05)$ in group 1,40 minutes after vasopressin administration. Twenty minutes after nitroglycerin and vasopressin an increase of the heart rate, albeit not significant, was seen, with simultaneous return to normal of the arterial systemic pressure. This could be ascribed to a reduction of the carotid sinus reflex, given that the administration of nitroglycerin alone had not produced any change of heart rate in group 2. 
The changes in arterio-venous oxygen difference observed during the experiment can be better understood by examining the time constant $(\tau)$ of the exponential growth function:

$\mathrm{Ca}_{\mathrm{O}_{2}} \mathrm{~m}-\mathrm{C} \overline{\mathrm{V}}_{\mathrm{O}_{2}}=\left(\mathrm{Ca}_{\mathrm{O}_{2}} \mathrm{~T}-\mathrm{C} \overline{\mathrm{V}}_{\mathrm{O}_{2}}\right)\left(1-\mathrm{e}^{-\mathrm{kt}}\right)$ which, $\mathrm{k}$ being $\tau^{-1}$, indicates the time used by the blood being examined to reach 63 per cent of the arterio-venous difference for arterial oxygen content with saturation of 100 per cent, taking into account the mixed venous oxygen content and measured arterial oxygen content. This is related to changes of pulmonary flow and the haemoglobin dissociation curve, since the variations of ventilation can be supposed to have a negligible effect because the animals were subjected to controlled ventilation. During the administration of vasopressin a renuction of $\tau$ was noted, partially corrected by the infusion of nitroglycerin which, administered separately in group 2, produced an increase of $\tau$.

This phenomenon could be ascribed to a redistribution of blood caused by nitroglycerin, with reduced pulmonary flow to the benefit of splanchnic flow and consequent reduction of pulmonary oxygenation, however negligible, the values of oxygen saturation being comparable in both groups.

These considerations are supported by the observation that the ischaemic colour of the intestinal loops with vasopressin infusion disappeared during the administration of nitroglycerin.

Although the clinical use of the combination of vasopressin and nitroglycerin needs further examination it would appear, to judge from our results, that nitroglycerin might be a suitable drug to prevent the side effects from the administration of vasopressin: nitroglycerin did not alter the portal hypotensive effects of vasopressin, contrary to other drugs such as isoproterenol, dopamine or glucagon which, in experiments by others, significantly reduced its efficacy when associated with vasopressin. Moreover, the low toxicity of nitroglycerin and the absence of tachyphylaxis make the combination of vasopressin and nitroglycerin preferable to that of vasopressin with sodium nitroprusside. ${ }^{5} \mathrm{Al}$ though Gelman and Ernest ${ }^{5}$ report that this combination is efficacious in preventing the disadvantages inherent in the use of vasopressin, it requires a concentration of red cells and of rodanase for its metabolism, ${ }^{10}$ which are not always present in the cirrhotic patients for whom the infusion of vasopressin might be destined. Also the fatal accidents reported in patients with hepatic insufficiency during the administration of sodium nitroprusside ${ }^{11}$ make the use of this hypotensive drug dangerous in cirrhotic patients.

\section{REFERENCES}

1. Nakano, J, Cardiovascular responses to neurohypophysial hormones. Hand-book of Physiology (Vol. IV, p 395). Edited by Knobil, E. and Sawyer, W.H. American Physiological Society, Washington (1974)

2. BaRR, J.V., Rakin, R.C. \& Rosch, J. Similarity of arterial and intravenous vasopressin on portal and systemic hemodynamics. Gastroenterology 69: $13-17$ (1975)

3. SKIVolocki, N.P. \& THomford, N.R. Addition of isoproterenol prevents adverse hemodynamic effects of vasopressin. Surgery 74: 752-757 (1973).

4. Tetiruck, C., Thomford, N.R., Pace, N.G., et al. The portal hypertensive effects of dopamine. J. Surg. Res. 22: 671-678 (1977).

5. Gelman, S. \& ERnst, E. Nitraprusside prevents adverse hemodynamic effects of vasopressin: Arch. Surg. 113: 1465-1471 (1978).

6. FERRARI, M. Farmacologia clinica cardiovascolare. Edited by Piccini editore, pp 120-130 Padova (1979).

7. NABIL, R. FAHMY, Nitroglycerin as hypotensive drug during general anesthesia: Anesthesiology 49: 17-20 (1978)

8. Maestracci, P. \& Mattie, M. Reperage de la position d'un catheter veneux grace a l'elettrocardiogramme endocavitaire. Ann. Anest. Franç. 12: $421-426$ (1971).

9. GroszmanN, R.J., Blei, A.T., Strorer, E.H., et al. Pharmacological vs. mechanical reduction in portal pressure: a comparative study. Surgery 84: 679-685, (1978).

10. Bouyard, P., Cotte, G., Bruguerolle, B., et al. Etude toxico-pharmacologie du nitroprussiate de sodium lyophilisé (NPS). Ann. Anest. Franc 18: 153-160 (1977)

11. Du Cailar, J., Mathie-Daude, J.C. \& DeSCHODT, J. Etude du taux plasmatique et eritrocytaire de l'jon cyanure au cours de la perfusion de nitroprussiate de sodium (NIPRIDE). Ann. Anest. Franç. 18: 178 (1977)

\section{RÉSUMÉ}

De nombreuses publications ont faite état de l'efficacité de la vasopressin dans le traitement des hémorrhagies digestives supérieures survenant chez les cyrrhotiques présentant une hypertension portale. Les effets indésirables de cet agent limitent fréquemment son usage. 
Ceci nous a amené à étudier l'association nitroglycérine-vasopressine. Le travail a été effectué chez le chine. Une perfusion de vasopressine, à raison de $0.25 \mathrm{U} \cdot \mathrm{kg}^{-1} \cdot \mathrm{min}^{-1}$ était d'abord administrée durant quarante minutes, puis on ajoutait une perfusion de nitroglycérine à la dose de $1.2 \mu \mathrm{g} \cdot \mathrm{kg}^{-1} \cdot \mathrm{min}^{-1}$. Ce protocole a été utilisé chez quatre chiens. Quatre autres chiens ont reçu uniquement la perfusion de nitroglycérine (à la même dose). Les paramètre étudiés étaient les pressions vieneuses centrales et mésentériques, les pressions artiérielles fémorales et mésentériques, l'électrocardiogramme et les différences artério-veineuses. La nitroglycérine a éliminé les effets indésirables de la vasopressine sans modifier l'efficacité de cet agent contre l'hypertension portale. 